\title{
UV-vis spectroscopic study of lipid peroxidation and antioxidant contents of kidney of Albino mice co-administrated with sildenafil citrate and alcohol
}

\author{
K. Soumya ${ }^{\mathrm{a}, *}$, Raju Udayakumar ${ }^{\mathrm{b}}$ and K. Viswanathan ${ }^{\mathrm{a}}$ \\ ${ }^{a}$ Department of Physics, Karpagam University, Coimbatore, Tamil Nadu, India \\ ${ }^{\mathrm{b}}$ Department of Physics, Faculty of Science, Annamalai University, Annamalai Nagar, Tamil Nadu, \\ India
}

\begin{abstract}
Male Wistar Albino mice were co-administrated with appropriate dose of sildenafil citrate and alcohol. The kidney samples of those animals were analyzed for lipid peroxidation and antioxidant contents. Lipid peroxidation was measured based on TBARS. Antioxidant such as SOD, CAT, GPx and GSH were also determined. From the present investigation, an enhanced level of TBARS accompanied by a decreased concentration of enzymic as well as non-enzymic antioxidants in kidney was detected for 30 days animals treated concomitantly with sildenafil citrate and alcohol. Increased level of lipid peroxidation lead to accumulation of free radicals and increased oxidative threat in kidney tissues. Also, the decreased concentration of antioxidant enzymes in renal tissues indicates the failure of antioxidant defence system.
\end{abstract}

Keywords: Albino mice, kidney, sildenafil citrate, alcohol, lipid peroxidation, antioxidants

\section{Introduction}

The issue of erectile dysfunction provides a paradoxial situation to both the patients and physicians. Sildenafil citrate is reportedly an effective and safe medication [2] indicated for the treatment of ED. It is a competitive inhibitor of cGMP-Specific phosphodiesterase type 5. The medication amplifies the effects of sexual stimulation by regarding the degradation of this enzyme. Sildenafil has been found effective in several subpopulations of men with ED, including sufferers from diabetes, hypertension, spinal cord injuries [7], multiple sclerosis [11], depression [10,36], PTSD [25], men after resection of the prostate or radical prostatectomy [22], after renal transplant [30], men on dialysis [5] and men aged 65 years and older [3].

Studies conducted by Jeffcoate et al. [15] and McCambridge et al. [19] show that men with ED are frequently chronic alcohol addicts. The findings of previous studies show that modest ethanol doses (e.g., at blood concentrations of $\leqslant 100 \mathrm{mg} / \mathrm{dl}$ ) can both increase sexual drive and decrease erectile capacity in men [4]. As a result, alcohol dependent men commonly suffer from erectile dysfunction being an effective vasoactive agent currently available for the treatment of ED, most of them uses sildenafil citrate.

\footnotetext{
${ }^{*}$ Corresponding author: K. Soumya, Department of Physics, Karpagam University, Coimbatore, Tamil Nadu, India. E-mail: soumya.preethu@gmail.com.
} 
The combined use of sildenafil and alcohol may affect the biochemical balance of the body. In human body, kidneys are the organs primarily responsible for regulating the amounts and concentration of lipid peroxidative and antioxidant substances in extra cellular fluid. Hence, here, we choose the experimental organ as kidney.

Previous studies reveal that alcohol consumption leads to kidney swelling and reduced kidney function [37] and also, kidney cells get enlarged with increased amounts of protein, fat and water. Alcohol consumption reduces the amount of potassium excreted by the kidneys. Excessive alcohol consumption can have profound negative effects on the kidneys and their function in maintaining the body's fluid, electrolyte and acid-base balance, leaving alcoholic people vulnerable to a host of kidney related health problems [21]. These points must be kept in our mind during the analysis of this work.

The goal of the present study was whether the combined consumption of sildenafil citrate and alcohol affects the lipid peroxidation and antioxidant levels in the kidney tissues. We sought to examine (i) the concentration of lipid peroxidative substance such as TBARS, and (ii) the concentration of antioxidants such as SOD, CAT, GPx and GSH before and after the co-administration of sildenafil and alcohol.

\section{Materials and methods}

\subsection{Chemicals}

Drug, here, refers to the commercially available $50 \mathrm{mg}$ tablet of sildenafil citrate (VIAGRA). Alcohol was purchased from sigma chemical Co. (St Louis, MO, USA). All other chemicals utilized were of analytical grade and were obtained from local firms (India).

\subsection{Animals}

The local institutional animal ethics committee (Register number 160/1999/CPCSEA), Annamalai University, Annamalai Nagar, India, approved the experimental design. The animals were maintained as per the principles and guidelines of the ethical committee for animal care of Annamalai University in accordance with Indian National Law on animal care and use. Healthy male Wistar Albino mice (Mus musculus), with an initial body weight of $25-30 \mathrm{~g}$, were used in this study. The animals were housed in stainless steel mesh cages, housed under controlled conditions (temperature $25 \pm 2^{\circ} \mathrm{C}$, natural high-dark cycle). Commercial standard pellet diet (Hindustan lever Ltd, Mumbai, India) and drinking water were provided ab libitum. Six animals were usually tested as a group in each experiment. The commercial mice feed contained $5 \%$ fat, $21 \%$ protein, $55 \%$ nitrogen free extract and $4 \%$ fiber (w/w), with adequate minerals and vitamin contents.

\subsection{Experimental design}

The animals were randomly divided into seven groups of six animals each.

Groups S1: Control animals treated intragastrically with conductivity water (1 lig/gm body wt/day) for 30 days.

Group S2: Animals received drug orally (at $1 \mu \mathrm{g} / \mathrm{gm}$ body wt/day) for 15 days using intragastric tube.

Group S3: Animals received drug (at $1 \mu \mathrm{g} / \mathrm{gm}$ body wt/day administrated orally) for 30 days.

Group S4: Animals were treated with alcohol orally (at $0.01 \mu \mathrm{g} / \mathrm{gm}$ body wt/day) for 15 days using intragastric tube. 
Group S5: Animals were treated with alcohol orally (at $0.01 \mu \mathrm{g} / \mathrm{gm}$ body wt/day) for 30 days.

Group S6: Animals received drug (at $1 \mu \mathrm{g} / \mathrm{gm}$ body wt/day) followed by oral administration of alcohol (at $0.01 \mu \mathrm{g} / \mathrm{gm}$ body wt/day) for 15 days.

Group S7: Animals received drug (at $1 \mu \mathrm{g} / \mathrm{gm}$ body wt/day) followed by oral administration of alcohol (at $0.01 \mu \mathrm{g} / \mathrm{gm}$ body $\mathrm{wt} /$ day) for 30 days.

After four hours of drug administration, the animals were sacrificed by cervical decapitation. The kidney was dissected out and quickly rinsed in $4 \%$ saline. Tissue samples were dried and homogenized using appropriate buffer by Tefflon Pestle. The following parameters were estimated using UV-vis spectrophotometer.

\begin{tabular}{ll}
\hline Sl no. & Biochemical parameter \\
\hline 1 & TBARS \\
2 & GSH \\
3 & GPx \\
4 & SOD \\
5 & CAT \\
\hline
\end{tabular}

Lipid peroxidation in kidney was estimated by measuring thiobarbituric acid reactive substances (TBARS). TBARS was estimated using the method of Nichans and Samuelson [24] and reduced glutathione (GSH) by the method of Ellman [9]. Catalase (CAT) was assayed using the method of Sinha [31] and GPx by the method of Rotruck et al. [29]. Supreoxide dismutase (SOD) activity was determined by the modified method of NADH-phenazinemetho sulphate-nitroblue tetrazolicem formazon inhibitor reaction, measured spectro-photometrically at $560 \mathrm{~nm}$ [16].

\subsection{Statistical analysis}

All data were expressed as mean $\pm \mathrm{SD}$ of number of experiments $(n=6)$. The statistical significance was evaluated by one-way analysis of variance (ANOVA) using SPSS version 9.0 (SPSS, Cary, NC, USA) and the individual comparisons were obtained by Duncan's Multiple Range Test (DMRT). $P<$ 0.05 was considered to be statistically significant.

\section{Results}

Table 1 portrays the results of the level of lipid peroxidation in terms of TBARS and the concentration of antioxidants in terms of SOD, CAT, GPx and GSH, as carried out in the present study. Figure 1 illustrates the graphical representation of the level of TBARS for each sample. An enhanced level of TBARS in kidney has been noticed for all the experimental animals. However, statistically significant increase in TBARS concentration has been observed only for S3 (30 days drug treated), S5 (30 days alcohol treated), S6 (15 days 'drug + alcohol' treated) and S7 (30 days 'drug + alcohol' treated) groups of animals. The combined dosage of drug and alcohol administered continuously for 30 days, resulted in an elevated lipid peroxidation in kidney of Albino mice (Fig. 1).

Changes in SOD experiment have been detected in the case of kidney of Albino mice treated with the drug and alcohol, both individually and combinatorially. The decrement in SOD content has been observed to be statistically significant for S3 (30 days drug treated), S5 (30 days alcohol treated), S6 (15 days 'drug + alcohol' treated) and S7 (30 days 'drug + alcohol' treated) groups of animals (Fig. 2). 
Table 1

Thiobarbituric acid reactive substances (TBARS) and antioxidants content in kidney of Albino mice treated combinatorially with sildenafil citrate and alcohol

\begin{tabular}{|c|c|c|c|c|c|}
\hline \multirow[t]{2}{*}{ Group } & \multirow{2}{*}{$\begin{array}{l}\text { Concentration } \\
\text { of TBARS } \\
\text { (nmol/g tissue) }\end{array}$} & \multicolumn{4}{|c|}{ Concentration of antioxidants } \\
\hline & & $\begin{array}{c}\text { SOD } \\
\text { (unit/min/mg protein) }\end{array}$ & $\begin{array}{c}\text { CAT } \\
\left(\mu \mathrm{mol} \text { of } \mathrm{H}_{2} \mathrm{O}_{2}\right. \\
\text { consumed } / \mathrm{min} / \mathrm{mg} \text { protein })\end{array}$ & $\begin{array}{c}\text { GPx } \\
(\mu \mathrm{g} \text { of GSH } \\
\text { utilized/min/mg protein })\end{array}$ & $\begin{array}{c}\mathrm{GSH} \\
(\mu \mathrm{mol} / \mathrm{mg} \\
\text { protein })\end{array}$ \\
\hline$\overline{S 1}$ & $1.56 \pm 0.11^{\mathrm{a}}$ & $11.06 \pm 0.77^{\mathrm{a}}$ & $50.17 \pm 3.90^{\mathrm{a}}$ & $5.59 \pm 0.41^{\mathrm{a}}$ & $2.82 \pm 0.19^{\mathrm{a}}$ \\
\hline $\mathrm{S} 2$ & $1.79 \pm 0.11^{\mathrm{a}}$ & $10.80 \pm 0.80^{\mathrm{a}}$ & $47.52 \pm 3.28^{\mathrm{a}, \mathrm{b}}$ & $5.11 \pm 0.39^{\mathrm{a}, \mathrm{b}}$ & $2.76 \pm 0.17^{\mathrm{a}}$ \\
\hline S3 & $2.45 \pm 0.19^{b}$ & $10.05 \pm 0.72^{b}$ & $42.20 \pm 3.04^{\mathrm{c}}$ & $4.77 \pm 0.34^{\mathrm{b}}$ & $2.12 \pm 0.11^{\mathrm{c}}$ \\
\hline S4 & $1.69 \pm 0.13^{\mathrm{a}}$ & $10.31 \pm 0.79^{\mathrm{a}}$ & $48.11 \pm 3.66^{\mathrm{a}, \mathrm{b}}$ & $5.54 \pm 0.38^{\mathrm{a}}$ & $2.71 \pm 0.21^{\mathrm{a}}$ \\
\hline S5 & $2.03 \pm 0.14^{\mathrm{b}}$ & $10.92 \pm 0.76^{\mathrm{b}}$ & $44.14 \pm 3.88^{\mathrm{b}, \mathrm{c}}$ & $5.21 \pm 0.40^{\mathrm{a}, \mathrm{b}}$ & $2.45 \pm 0.19^{b}$ \\
\hline S6 & $2.12 \pm 0.11^{\mathrm{b}}$ & $10.56 \pm 0.70^{\mathrm{b}}$ & $46.69 \pm 3.56^{\mathrm{a}, \mathrm{b}}$ & $4.97 \pm 0.27^{\mathrm{b}}$ & $2.64 \pm 0.20^{\mathrm{a}, \mathrm{b}}$ \\
\hline S7 & $2.67 \pm 0.20^{\mathrm{c}}$ & $9.33 \pm 0.73^{\mathrm{c}}$ & $35.43 \pm 2.78^{\mathrm{d}}$ & $4.14 \pm 0.13^{\mathrm{c}}$ & $1.85 \pm 0.14^{\mathrm{d}}$ \\
\hline
\end{tabular}

Notes: Values are mean \pm SD of six mice from each group. Values not sharing a common superscript letter differ significantly at $P<0.05$ (DMRT), $P<0.05$ (ANOVA). TBARS - thiobarbituric acid reactive substances; $\mathrm{SOD}$ - superoxide dismutase; CAT - catalase; GPx - glutathione peroxidase; GSH - reduced glutathione. S1 - control; S2 - drug (15 days); S3 - drug (30 days); S4 - alcohol (15 days); S5 - alcohol (30 days); S6 - drug + alcohol (15 days); S7 - drug + alcohol (30 days).

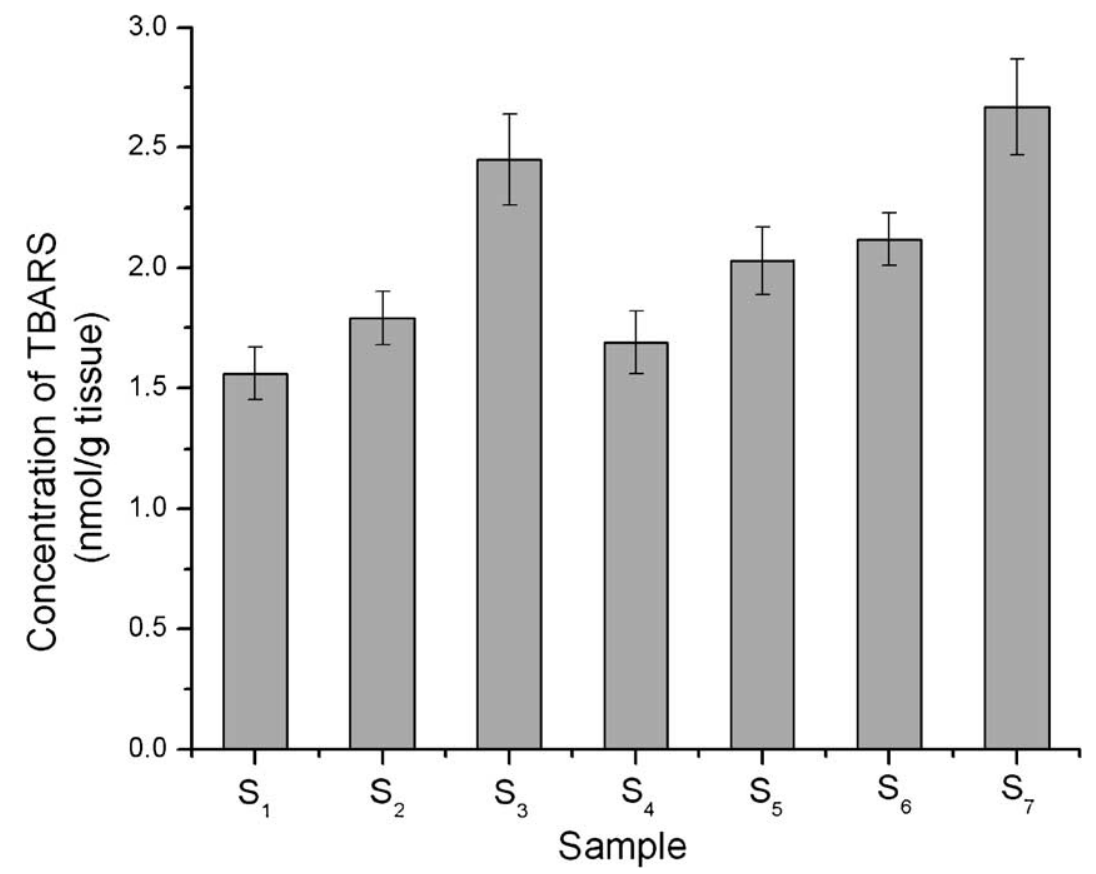

Fig. 1. Change in the concentration of thiobarbituric acid reactive substances (TBARS) in kidney of control and experimental Albino mice. S1 - control; S2 - drug (15 days); S3 - drug (30 days); S4 - alcohol (15 days); S5 - alcohol (30 days); S6 drug + alcohol (15 days); S7 - drug + alcohol (30 days).

Prominent variations in the concentration of CAT have been noticed for the kidney samples of all the experimental Albino mice, compared to the control ones. The level of CAT has been found to decrease with the duration of the experiment and it is the least for S7 (30 days 'drug + alcohol' treated) group of animals (Fig. 3). 


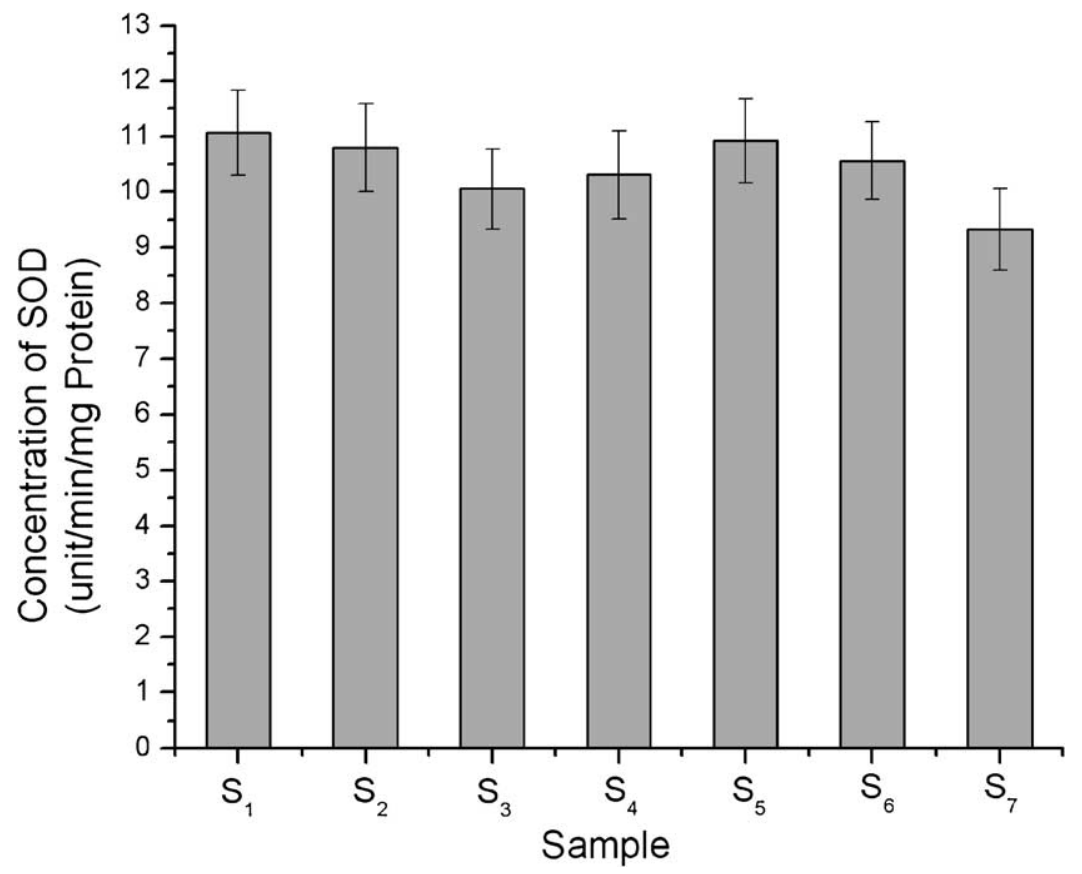

Fig. 2. Change in the concentration of superoxide dismutase (SOD) in kidney of control and experimental Albino mice. S1 control; S2 - drug (15 days); S3 - drug (30 days); S4 - alcohol (15 days); S5 - alcohol (30 days); S6 - drug + alcohol (15 days); S7 - drug + alcohol (30 days).

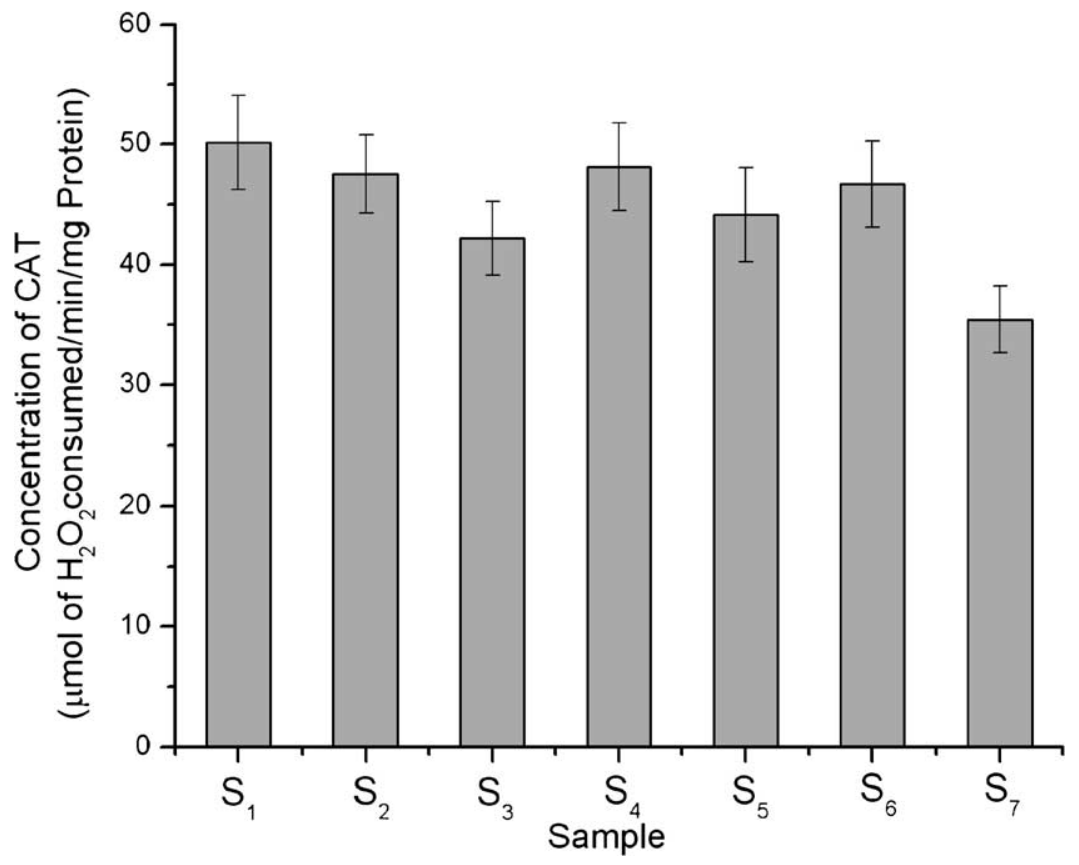

Fig. 3. Change in the concentration of catalase (CAT) in kidney of control and experimental Albino mice. S1 - control; S2 drug (15 days); S3 - drug (30 days); S4 - alcohol (15 days); S5 - alcohol (30 days); S6 - drug + alcohol (15 days); S7 drug + alcohol (30 days). 


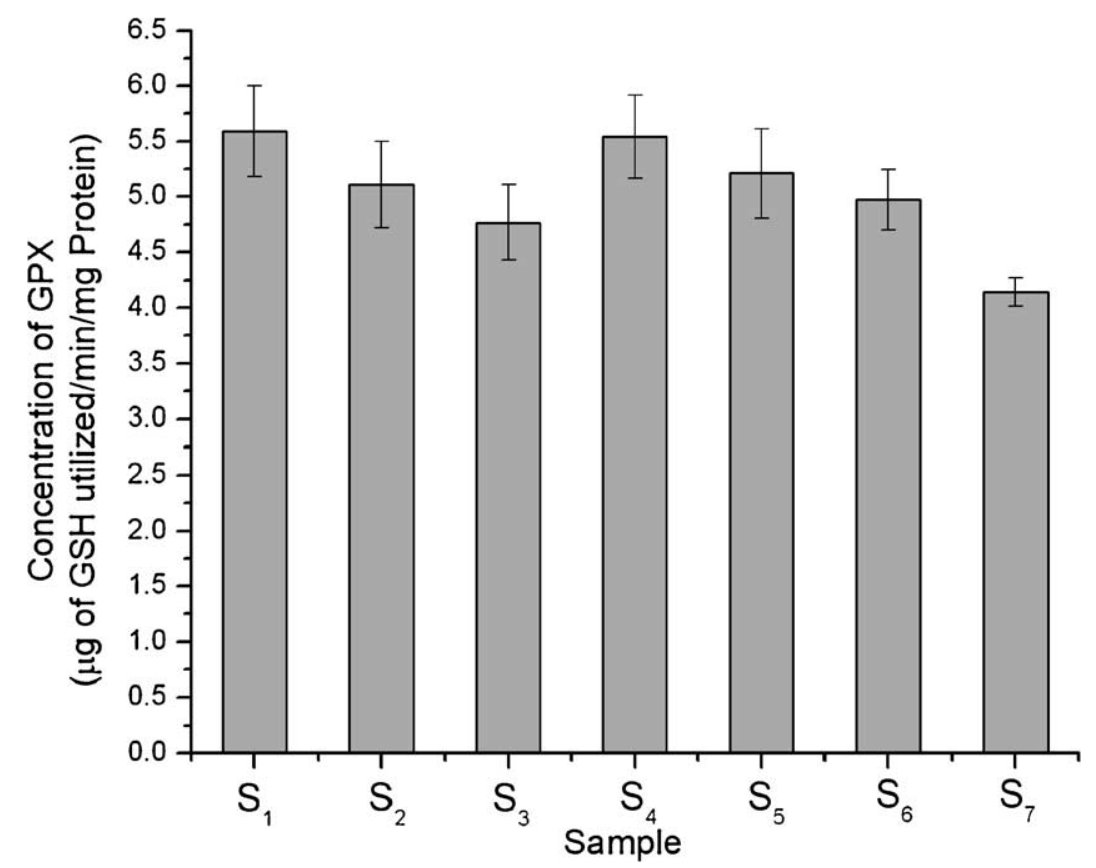

Fig. 4. Change in the concentration of glutathione peroxidase (GPx) in kidney of control and experimental Albino mice. S1 control; S2 - drug (15 days); S3 - drug (30 days); S4 - alcohol (15 days); S5 - alcohol (30 days); S6 - drug + alcohol (15 days); $\mathbf{S} 7$ - drug + alcohol (30 days).

A close scrutiny of Table 1 indicates the fact that the level of GPx had fallen significantly with the duration of the drug treatment. The concomitant administration of the drug and alcohol to Albino mice culminates in rapid decrease in the concentration of GPx, as compared to S1 (control) group of animals (Fig. 4).

The data presented in Table 1 show that the continuous treatment of drug to Albino mice for 15 days did not produce any tangible alterations in GSH environment while the 30 days drug treatment resulted in a statistically significant fall in it. Similar trend has also been noticed for alcohol treatment. However, the combined dosage of drug and alcohol to Albino mice end up in significant decrease in GSH level in kidney of these animals (Fig. 5).

\section{Discussion}

From the present study, it is well understood that the combined administration of sildenafil citrate and alcohol induced lipid peroxidation (LP) as well as had an inhibitory effect on the antioxidant enzymes.

Membrane lipid peroxidation plays an important role in cell physiology and pathology and the products formed during this process have been noticed to produced unfavorable effects locally as well as far from their site of formation [28]. According to Mayya et al. [26], LP is a destructive process and the toxic products formed during it are more responsible for the membrane damage. The participation of these products in membrane fusion has been reported by De Duve et al. [6]. The disorders in lipid organization of biological membranes result in alterations in the activity of a number of membrane bound enzymes [13]. A close correlation between the membrane lipid peroxidation and some of the cell functions as well as many pathological processes has been observed by Eduards et al. [8]. 


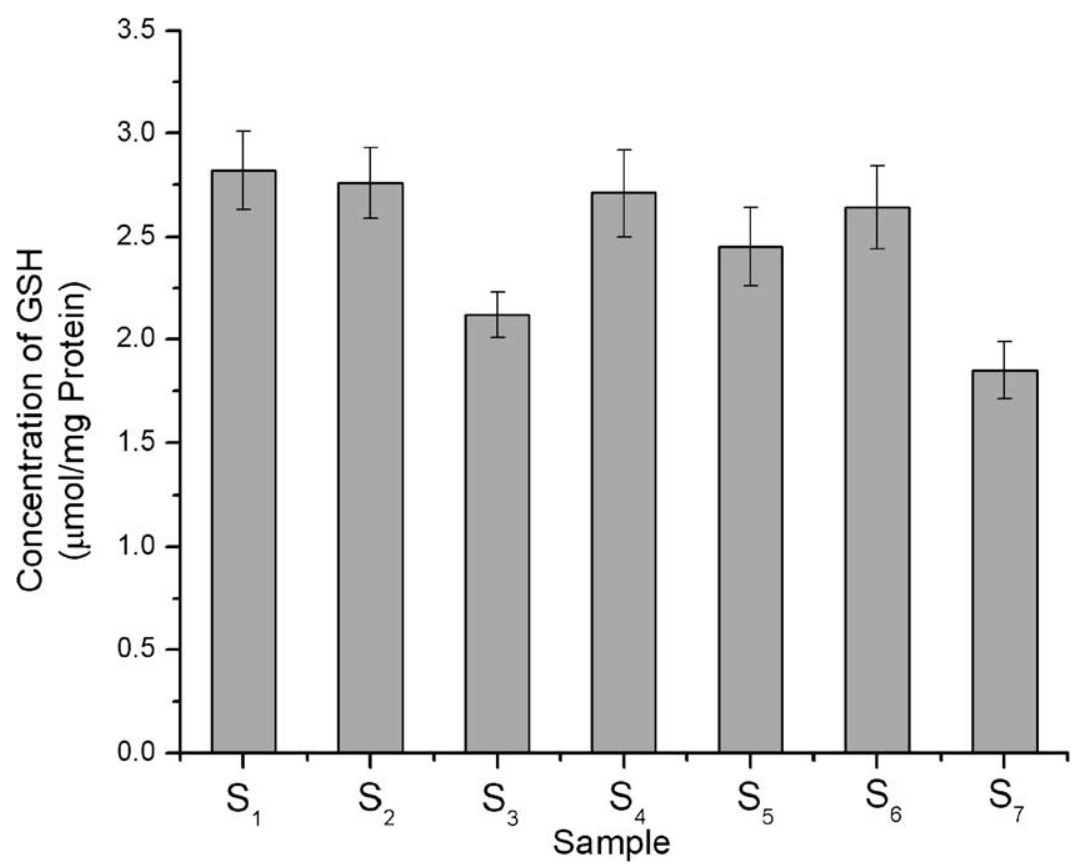

Fig. 5. Change in the concentration of reduced glutathione (GSH) in kidney of control and experimental Albino mice. S1 control; S2 - drug (15 days); S3 - drug (30 days); S4 - alcohol (15 days); S5 - alcohol (30 days); S6 - drug + alcohol (15 days); $\mathrm{S} 7$ - drug + alcohol (30 days).

Increases in lipid peroxidation leads to cell damage. According to Karine et al. [1], once lipid peroxidation is initiated, it can easily be propagated in the cellular environment where unsaturated lipids and oxygen are present. The oxidation of lipids is propagated by radical mediated chain reactions. Malon dialdehyde (MDA) and a wide rage of other oxidation products are formed due to these chemical processes. Formation of MAD and other aldehydes has been regarded as significant because these compounds are toxic, mutagenic, tumerigenic and genotoxic [34]. Powerful damage to subcellular structures has occurred due to LP [26].

Co-administration of sildenafil and alcohol induces lipid peroxidation that could alter the structure and function of the cellular membrane and block cellular metabolism leading to cytotoxicity, i.e., possibility to inhibition of synthesis of cellular macromolecules.

Lipid peroxidation affects plasma membrane integrity as well as that of the nucleus and other cellular organelles lipid peroxidation may also be related to the disturbances of cell signaling processes, genotoxicity, mutagenicity and tumor promotion.

Enhanced lipid peroxidation constitutes a complex chain reaction of free radicals, while leads to a degradation of polyunsaturated fatty acid in cell membranes [12]. Free radicals cause cell injury by damaging lipids, protein and DNA if generated in excess or else antioxidant defence mechanism is impaired and may ultimately result in damage to many systems in the body. The lipid composition determines the fluidity, stability and permeability of membranes and there by influences the function of enzymes, ion channels and receptors.

In the present investigation, high levels of lipid peroxidation were detected in kidney of Albino mice treated with sildenafil and alcohol. The imbalance between production and elimination of free radicals 
can induce extensive cellular membrane damage and influence many cellular functions such as enzyme activity, receptor activation, release of transmitters, membrane permeability and ion channel function.

Sildenafil citrate and alcohol disrupt the antioxidant balance of tissues that leads to biochemical and physiological dysfunction [23]. Peroxidation of lipids, implicated in wide variety of physiological events, is a complex process that occurs during innumerable pathological condition [17]. Peroxide formation in vivo many produce serious consequences in the tissues such as oxidative destruction of thiol groups of amino acids and proteins [18]. Lipids, particularly unsaturated fatty acids, are damaged directly by free radical oxidation. Peroxidative damages induced in the cell are encountered by the elaborate defence mechanisms including enzymic and non-enzymic antioxidants [14].

Numerous studies demonstrate that changes in the antioxidant system and impairment of sodium and potassium transport are essential factors involved in the kidney tissues [32]. Evidences suggest that the excessive production of free radicals and the imbalance between oxidative species and antioxidant defence is related to the pathogenesis of neurodegenerative diseases [39].

The significant decrease in the levels of non-enzymic antioxidants, as observed in the present study, could lead to increased susceptibility of the tissue to free radical damage. The decreased concentration of antioxidant enzymes were observed in the renal tissue of the present work, which indicate the failure of antioxidant defence system. Thus, the inhibition of enzymes involved in free radical removal leads to the accumulation of $\mathrm{H}_{2} \mathrm{O}_{2}$, which promotes lipid peroxidation and modulation of DNA altered gene expression and cell death $[33,38]$.

SOD constitutes an important link in the biological defence mechanism through disposition of endogenous cytotoxic superoxide radicals that are deleterious to polyunsaturated fatty acids (PUFA) and structural proteins of plasma membrane. So, decrease in concentration of SOD, due to the combined dosage of drug and alcohol will adversely affect the biological defence mechanism. The inhibition of CAT and GPx results in excessive accumulation of $\mathrm{H}_{2} \mathrm{O}_{2}$ in the mitochondria and peroxisomes or cytosol or both [20]. According to Rister et al. [27], increased lipid peroxidation may result in the accumulation of $\mathrm{H}_{2} \mathrm{O}_{2}$, thereby CAT activity decreases and hence, it may result in oxidative stress.

GSH plays a key role in cellular defence against toxic chemicals. It is well established that the nonenzymic antioxidants such as vitamin C and vitamin E concomitantly decreased with GSH [35]. GSH is the most abundant non-protein thiol that maintains the cellular redox status and providing first line of antioxidant protection against oxidative stress. So, low concentration of GSH due to the concomitant administration of drug and alcohol, as noticed in the present work, may reversely affect the oxidant defence.

Hence, it is concluded from the present investigation that the decreased activities of antioxidant systems and the increased level of lipid peroxidation may ultimately lead to the accumulation of free radicals and increased oxidative threat in tissue.

\section{Acknowledgements}

Authors would like to thank the staff members of Animal House, Rajah Muthiah Medical College, Annamalai Nagar, Chidambaram, Tamil Nadu. The authors also extended their sense of gratitude to staffs in Biochemistry Lab, Annamalai University, Annamalai Nagar, for giving permission to access the UV-vis facility to record the spectra of the samples. 


\section{References}

[1] K. Abado Becognee, T. Amondo Mobio, R. Ennamay and F. Fluerat Lessard, Cytotoxicity of fumonisin B1: implication of lipid peroxidation and inhibition of protein and DNA syntheses, Arch. Toxicol. 72 (1998), 233-236.

[2] A. Basu and R.E. Ryder, New treatment options for erectile dysfunction in patients with diabetes mellitus, Drugs 64 (2004), 2667-2688.

[3] C.C. Carson, Erectile dysfunction: evaluation and new treatment options, Psychosomatic Med. 66 (2004), 644-671.

[4] D. Caspari, E.H. Huebgen and H. Derociet, Interdisciplinary assessment and follow-up of patients with erectile dysfunction psychiatric aspects, Int. J. Importance Res. 11 (1999), 213-217.

[5] G. Dachille, V. Pagliaralo and G.H. Ludovico, Sexual dysfunction in patients under dialytic treatment, Minerva Urologica e Nefrologica 58 (2006), 195-200.

[6] C. De Dave and R. Wattiaus, Functions of lysosomes, Annu. Rev. Physiol. 28 (1966), 435-492.

[7] D. Deforge, J. Blackmer and C. Garritty, Male erectile dysfunction following spinal accord injury: a systematic review, Spinal Cord 44 (2006), 465-473.

[8] R.H. Eduards, D.A. Jones and M.J. Jackson, An approach to treatment trials in muscular dystrophy with particular reference to agents influencing free radical damage, Med. Biol. 62 (1984), 143-147.

[9] G.L. Ellman, Tissue sulphydryl groups, Arch. Biochem. Biophys. 82 (1959), 70-77.

[10] M. Fava, H.G. Nurnbay and S.N. Seidman, Efficacy and safety of sildenafil in men with serotonergic antidepresent associated erectile dysfunction. Results from a randomized, double blind, placebo controlled trial, J. Clin. Psychiatry 67 (2006), 240-246.

[11] C.J. Fowler, J.R. Miller and M.K. Sharief, A double blind, randomized study of sildenafil citrate for erectile dysfunction in men with multiple sclerosis, J. Neurol. Neurosur. Psychiatry 76 (2005), 700-705.

[12] B. Halliwell and J.M.C. Gutteridge, Lipid peroxidation oxygen radicals, cell damage and antioxidant therapy, Lancet 1 (1984), 1396-1397.

[13] J. Hogberg, A. Bergstrand and S.V. Jackbson, Lipid peroxidation of rat-liver microsomes. Its effect on the microsomal membrane and some membrane bound microsomal enzymes, Eur. J. Biochem. 37 (1973), 51-59.

[14] Y.M.W. Janson, B.V. Houten, P.J.A. Borm and B.T. Mossman, Biology of disease cell and tissue response to oxidation damages, Lab. Invest. 69 (1993), 261-274.

[15] W.J. Jeffcoate, The investigation of impotence, Br. J. Urol. 68 (1991), 499-453.

[16] P. Kakkar, B. Das and P.N. Viswanathan, A modified spectroscopic assay of superoxide dismutase, Indian J. Biochem. Biophys. 21 (1984), 130-132.

[17] D.J. Kornbrust and R.D. Mavis, Relative susceptibility of microsomes from lung, heart, liver, kidney brain and testis to lipid peroxidation. Correction with vitamin E content, Lipids 15 (1979), 135-322.

[18] S.E. Lewis and E.D. Wills, Destruction of -SH groups of proteins and amino acids by peroxides of unsaturated fatty acids, Biochem. Pharmacol. 11 (1962), 901-912.

[19] J. McCambridge, L. Mitcheson, N. Hunt and A. Winstock, The rise of Viagra among British illicit drug users: 5 year survey data, Drug Alcohol Rev. 25 (2006), 111-113.

[20] M. Minami, K. Koshi, K. Homma and Y. Suzuki, Changes of the activities of superoxide dismutase after exposure to the fume of heavy metals and the significance of zinc in the tissue, Arch. Toxicol. 49 (1982), 215-225.

[21] M.D. Murey Epstein, Alcohol's impact on kidney function, Alcohol Health Res. World 21(1) (1997), 84-90.

[22] K.C. Nandipati, R. Raince, A. Agrarwal and C.D. Zippe, Erectile dysfunction following radical retropunic prostatectomy: epidemiology, pathophysiology and pharmacological management, Drugs Aging 23 (2006), 101-117.

[23] R. Neal, K. Cooper, H. Gurer and N. Ercal, Effects of nacetyl cysteine and 2,3-dimercaptosuceinic acid on lead induced oxidative stress in rat lenses, Toxicology 130 (1998), 167-174.

[24] W.G. Nichius and D. Samuelsson, Formation of malondialdeny from phospholipids arachidonate during microsomal lipid peroxidation, Eur. J. Biochem. 6 (1968), 126-130.

[25] G. Orr, M. Weiser and M. Polliack, Effectiveness of sildenafil in treating erectile dysfunction in PTSD patients: a doubleblind placebo-controlled crossover study, J. Clin. Phychopharmacol. 26 (2006), 426-430.

[26] M. Popova and C. Popova, Damage to subcellular structures evoked by lipid peroxidation, Z. Naturforsch. 57C (2002), 361-364.

[27] M. Rister and R.L. Bachner, The alteration of superoxide dismutase, catalase, glutathione peroxidase and NAD $(P) H$ cytochrome-C reductase in guinea pig polymorphonuclear leukocytes and alveolar macrophages during hypoxia, J. Clin. Invest. 58 (1976), 1174-1184.

[28] M.K. Roders, E.A. Glende and R.O. Rechnagel, NADPH dependent microsomal lipid peroxidation and the problem of pathological action at a distance. New data on induction of red cell damage, Biochem. Pharm. 27 (1978), 437-443.

[29] J.T. Rotruck, A.L. Pope and H.E. Ganther, Selenium: biochemical role as a component of glutathione peroxidase purification assay, Science 179 (1973), 588-590. 
[30] R.K. Sharma, N. Prasad, A. Gupta and R. Kapoor, Treatment of erectile dysfunction with sildenafil citrate in renal allograft recipients: a randomized, double-blind, placebo-controlled, crossover trial, Am. J. Kidney Dis. 48 (2006), 128-133.

[31] A.K. Sinha, Calorimetric assay of catalase, Anal. Biochem. 47 (1972), 389-394.

[32] V.S. Slyshenkov, A.A. Shevalye, A.V. Liopo and L. Wojtezak, Protective role of L-methionine against free radical damage of rat brain synaptosomes, Acta Biochim. Pol. 4 (2002), 907-916.

[33] S.J. Stohs, D. Bagechi, E. Hassoun and M. Bagechi, Oxidative mechanisms in the toxicity of chromium and cadmium ions, J. Environ. Pathol. Toxiocol. Oncol. 19 (2000), 201-213.

[34] F.W. Summerfield and A.L. Tappel, Detection and measurement by high-performance liquid chromatograph of malondialdehyde crosslinks in DNA, Anal. Biochem. 143 (1984), 265-271.

[35] S. Sunitha, M. Nagaraj and P. Varalakshmi, Hepa to protective effect of lupcol and lupeol lineleate on tissue antioxidant defence system in cadmium induced hepatotoxicity in rats, Fitoterapia 72 (2001), 516-552.

[36] J. Tignol, P.M. Furlan and M. Gomez-Beneyto, Efficacy of sildenafil citrate (Viagra) for the treatment of erectile dysfunction in men in remiss from depression, Int. Clin. Psychopharmacol. 19 (2004), 191-199.

[37] D.H. Van Thiel, W.D. Williams, J.S. Gavaler, J.M. Little, L.W. Estes and B.S. Rabin, Ethnol - its nephrotoxic effect in the rat, Am. J. Pathol. 89(1) (1997), 67-84.

[38] M. Weisbery, P. Joseph, B. Hale and D. Begersman, Molecular mechanisms of cadmium carcinogenesis, Toxicology 192 (2003), 95-117.

[39] Y. Zhu, P.M. Carvey and Z. Ling, Age related changes in glutathione and glutathione-related enzymes in rat brain, Brain Res. 1090 (2006), 35-44. 


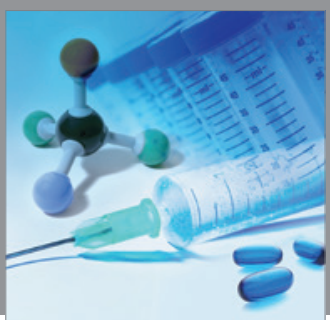

International Journal of

Medicinal Chemistry

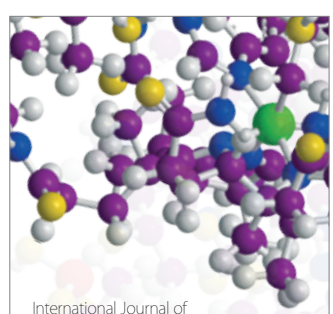

Carbohydrate Chemistry

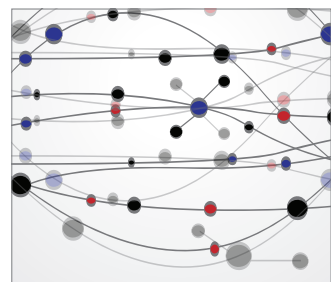

The Scientific World Journal
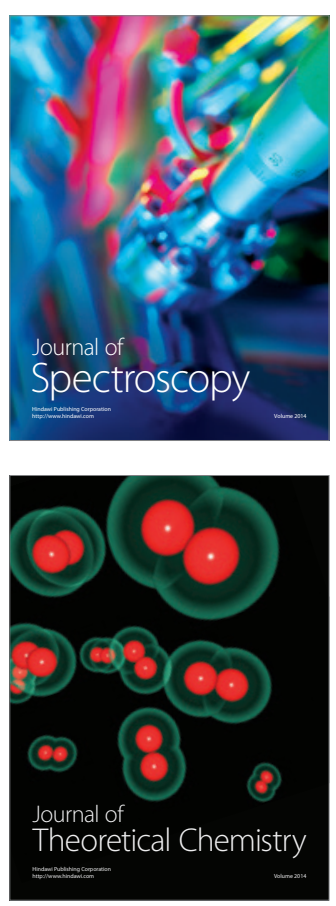
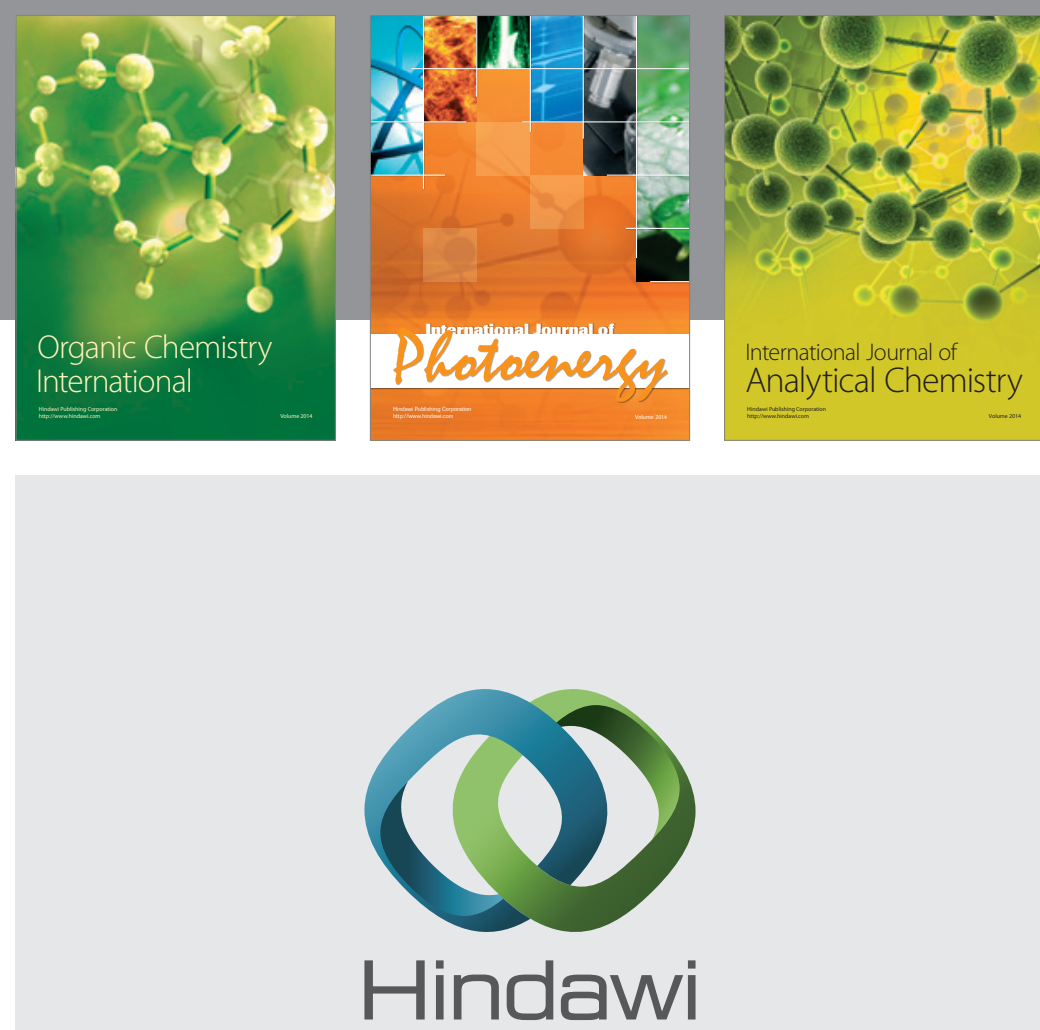

Submit your manuscripts at

http://www.hindawi.com
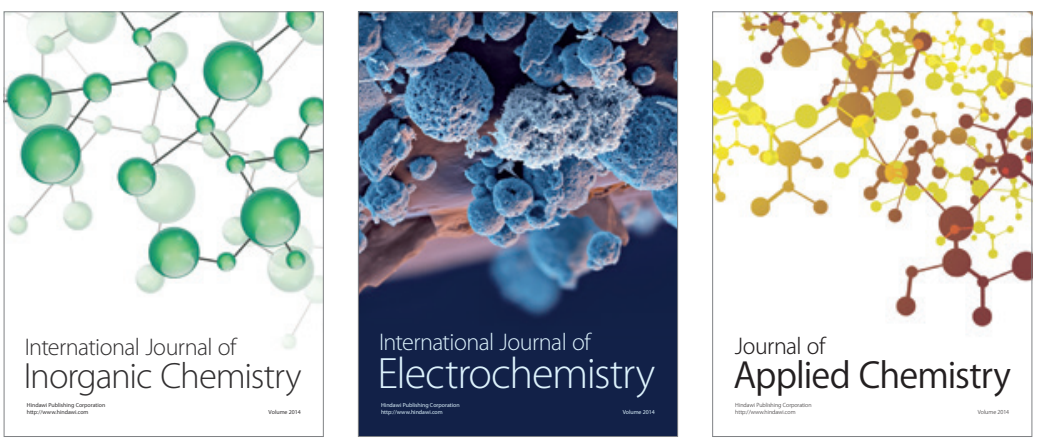

Journal of

Applied Chemistry
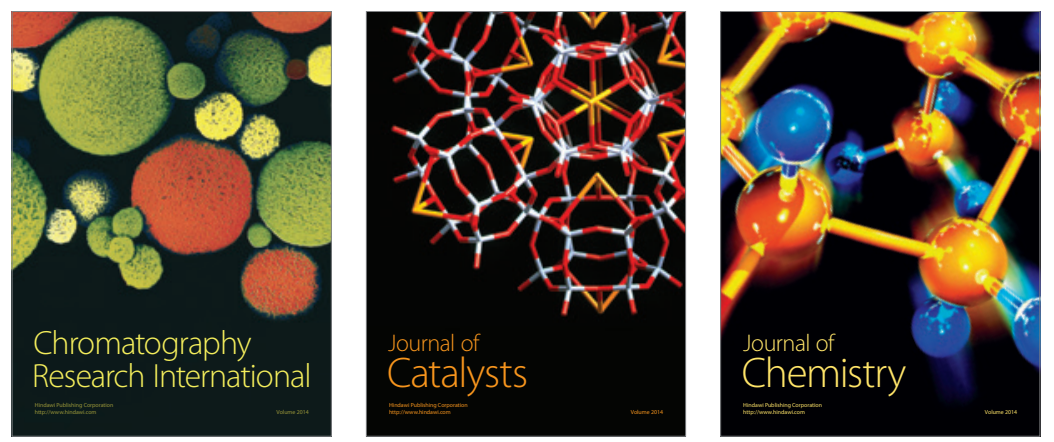
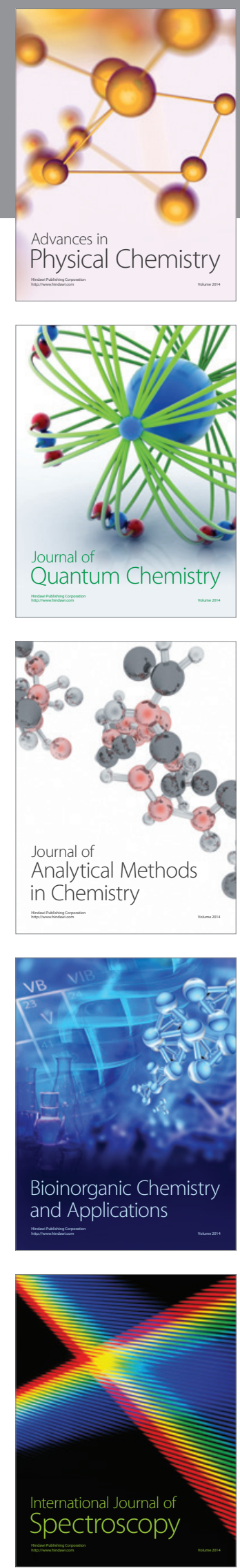